\title{
Breast cancer epidemiology according to recognized breast cancer risk factors in the Prostate, Lung, Colorectal and Ovarian (PLCO) Cancer Screening Trial Cohort
}

\author{
James V Lacey Jr*1, Aimee R Kreimer ${ }^{2,3}$, Saundra S Buys ${ }^{4}$, Pamela M Marcus ${ }^{5}$, \\ Shih-Chen Chang6,7, Michael F Leitzmann"7,8, Robert N Hoover9, \\ Philip C Prorok ${ }^{5}$, Christine D Berg${ }^{2}$, Patricia Hartge ${ }^{9}$ for the Prostate, Lung, \\ Colorectal and Ovarian (PLCO) Cancer Screening Trial Project Team
}

\begin{abstract}
Address: ${ }^{1}$ Hormonal and Reproductive Epidemiology Branch, Division of Cancer Epidemiology and Genetics, National Cancer Institute, National Institutes of Health, Rockville, Maryland, USA, ${ }^{2}$ Early Detection Research Group, Division of Cancer Prevention, National Institutes of Health, Rockville, Maryland, USA, ${ }^{3}$ Infections and Immunoepidemiology Branch, Division of Cancer Epidemiology and Genetics, National Cancer Institute, National Institutes of Health, Rockville, Maryland, USA, ${ }^{4}$ Department of Internal Medicine, Huntsman Cancer Institute, University of Utah Health Sciences Center, Salt Lake City, Utah, USA, ${ }^{5}$ Biometry Research Group, Division of Cancer Prevention, National Institutes of Health, National Cancer Institute, Rockville Maryland, USA, ${ }^{6}$ Global Epidemiology Department, AstraZeneca, Wilmington, Delaware, USA, ${ }^{7}$ Nutritional Epidemiology Branch, Division of Cancer Epidemiology and Genetics, National Cancer Institute, National Institutes of Health, Rockville, Maryland, USA, ${ }^{8}$ Institute of Epidemiology and Preventive Medicine, University of Regensburg, Regensburg, Germany and ${ }^{9}$ Epidemiology and Biostatistics Program, Division of Cancer Epidemiology and Genetics, National Cancer Institute, National Institutes of Health, Rockville Maryland, USA

Email: James V Lacey* - jimlacey@nih.gov; Aimee R Kreimer - kreimera@mail.nih.gov; Saundra S Buys - saundra.buys@hci.utah.edu; Pamela M Marcus - marcusp@mail.nih.gov; Shih-Chen Chang - Shih-Chen.Chang@astrazeneca.com; Michael F Leitzmann - michael.leitzmann@klinik.uni-regensburg.de; Robert N Hoover - hooverr@mail.nih.gov; Philip C Prorok - prorokp@mail.nih.gov; Christine D Berg - bergc@mail.nih.gov; Patricia Hartge - hartgep@mail.nih.gov; the Prostate, Lung, Colorectal and Ovarian (PLCO) Cancer Screening Trial Project Team - jimlacey@nih.gov

* Corresponding author
\end{abstract}

Published: 17 March 2009

BMC Cancer 2009, 9:84 doi:10.1 186/147|-2407-9-84
Received: 12 June 2008

Accepted: 17 March 2009

This article is available from: http://www.biomedcentral.com//47I-2407/9/84

(C) 2009 Lacey et al; licensee BioMed Central Ltd.

This is an Open Access article distributed under the terms of the Creative Commons Attribution License (http://creativecommons.org/licenses/by/2.0), which permits unrestricted use, distribution, and reproduction in any medium, provided the original work is properly cited.

\begin{abstract}
Background: Multidisciplinary attempts to understand the etiology of breast cancer are expanding to increasingly include new potential markers of disease risk. Those efforts may have maximal scientific and practical influence if new findings are placed in context of the well-understood lifestyle and reproductive risk factors or existing risk prediction models for breast cancer. We therefore evaluated known risk factors for breast cancer in a cancer screening trial that does not have breast cancer as a study endpoint but is large enough to provide numerous analytic opportunities for breast cancer.

Methods: We evaluated risk factors for breast cancer $(N=2085)$ among 70,575 women who were randomized in the Prostate, Lung, Colorectal and Ovarian Cancer Screening Trial. Using Poisson regression, we calculated adjusted relative risks [RRs, with $95 \%$ confidence intervals $(\mathrm{Cls})]$ for lifestyle and reproductive factors during an average of 5 years of follow-up from date of randomization.
\end{abstract}

Results: As expected, increasing age, nulliparity, positive family history of breast cancer, and use of menopausal hormone therapy were positively associated with breast cancer. Later age at 
menarche $(16$ years or older vs. $<12: \mathrm{RR}=0.8 \mathrm{I}, 95 \% \mathrm{Cl}, 0.65-\mathrm{I} .02)$ or menopause (55 years or older vs. < 45: $\mathrm{RR}=1.29,95 \% \mathrm{Cl}, \mathrm{I} .03-1.62)$ were less strongly associated with breast cancer than was expected. There were weak positive associations between taller height and heavier weight, and only severe obesity [body mass index $\left(\mathrm{BMI} ; \mathrm{kg} / \mathrm{m}^{2}\right) 35$ or more vs. 18.5-24.9: $\mathrm{RR}=1.2 \mathrm{I}, 95 \% \mathrm{Cl}$, I.02-1.43] was statistically significantly associated with breast cancer.

Conclusion: The ongoing PLCO trial offers continued opportunities for new breast cancer investigations, but these analyses suggest that the associations between breast cancer and age at menarche, age at menopause, and obesity might be changing as the underlying demographics of these factors change.

Clinical Trials Registration: http://www.clinicaltrials.gov, NCT00002540.

\section{Background}

Environment, genes, and lifestyle work together to increase or decrease the probability of developing female breast cancer [1]. Events early and late in life consistently influence breast cancer risk [2], but it remains difficult to explain why some women develop breast cancer and others do not [3]. This complicates prevention, yet some groups consistently have notably higher risks than other groups: women whose relatives have breast cancer [4], who first give birth later in life [5], who use exogenous hormones for extended durations [6], and who are overweight or obese after menopause [7].

Most of these conclusions were drawn from individual studies conducted in the 1970s through the late 1990s, or collaborative efforts to quantify risk across many studies [8-10]. Whereas many early studies were exploratory (because risk factor associations were less clear) contemporary studies can have additional or alternative aims, such as searching for molecular markers, evaluating risk among younger women or under-studied racial/ethnic groups, or testing new and refined risk prediction models. Expanding the breast cancer literature this way is obviously necessary, but a logical approach for these studies would be to determine whether the epidemiology of breast cancer in newer studies matches or differs from the published literature to date; because these new foci will likely be most fruitful if placed within the context of known risk factors for breast cancer, both to see whether markers modify those risks or are independently associated with those risk factors [11]. The Prostate, Lung, Colorectal, and Ovarian (PLCO) Cancer Screening Trial [12], although not primarily a breast cancer study, includes extensive data with which to test and develop hypotheses about breast cancer etiology. We therefore analyzed relative risk estimates for etiologic factors linked to breast cancer using the extensive questionnaire data from the approximate 75,000 post-menopausal women in the PLCO study.

\section{Methods}

\section{Study population}

Prorok et al. [13] previously described the full details of the PLCO trial, which includes both men and women. This analysis only includes women. The National Cancer Institute (NCI) designed this trial to determine whether routine screening with chest $\mathrm{X}$-ray, flexible sigmoidoscopy, and cancer antigen 125 (CA-125) plus transvaginal ultrasound could reduce mortality from lung, colorectal, and ovarian cancers, respectively (Clinical Trials Registration: http://www.clinicaltrials.gov, NCT00002540). Recruitment occurred at ten U.S. screening centers (SCs) between 1993 and 2001. Women were considered eligible if they were between ages 55 and 74 and had no previous diagnosis of lung, colorectal, or ovarian cancer. Women who were receiving cancer treatment or participating in another screening or prevention trial were ineligible. Women who had bilateral oophorectomy or were taking tamoxifen were originally ineligible but later allowed to enroll. All participants provided informed consent. Institutional review boards at the NCI and each screening center approved the study. Although the current analysis does not address the PLCO trial's main objectives, the PLCO trial follows the Consolidated Standards of Reporting Trials guidelines [14].

Within-center age- and sex-stratified randomization assigned women to either a control arm, where they were asked to follow their usual medical care, or an intervention arm, where they were offered screening at regular intervals [13]. Participants completed a self-administered risk factor questionnaire at entry, which queried information on demographics, smoking, history of cancer in firstdegree relatives, anthropometry, personal medical and medication use history, and personal history of cancer screening tests. Reproductive history covered menarche and menopause, parity and age at first pregnancy, and gynecologic surgeries, including hysterectomy, oophorectomy, and tubal ligation. The questionnaire ascertained age at first use and total duration of use of oral contraceptives. For menopausal hormone therapy, the question- 
naire asked about ever-use, current use, and duration of use but did not differentiate estrogen-only formulations from estrogen plus progestin.

\section{Cancer Ascertainment}

Participants received a mailed annual study update (ASU) around each anniversary of their randomization date. The ASUs ascertained the type and date of any cancer diagnosed in the previous year. Study staff contacted nonresponding participants by mail and telephone. To validate the self-reported cancers, staff retrieved medical records (for standardized medical record abstraction of pathology reports), death certificates, data from state cancer registries, and information from next-of-kin for deceased participants.

Of 78,231 enrollees $(39,116$ in the control arm and 39,115 in the intervention arm), 2085 women were diagnosed with breast cancer (including 388 carcinomas in situ) through May 31, 2003. This included 121 (5.8\%) self-reported (i.e., unconfirmed) and 1964 (94.2\%) confirmed breast cancers. Except where noted, self-reported breast cancers from both arms were included as study endpoints for this analysis; incidence did not differ between arms (data not shown).

\section{Statistical Analysis}

Analysis excluded 659 women (353 from the intervention arm and 306 from the control arm) who never returned an ASU form (and thus for whom breast cancer status was unknown) and women who reported a positive $(\mathrm{N}=$ $5119)$ or unknown $(\mathrm{N}=1878)$ personal history of any cancer before randomization. We considered the 70,575 remaining women at risk for developing breast cancer from the date they completed their baseline questionnaire until the first of the following: breast cancer diagnosis, death, or last ASU.

Follow-up is scheduled for at least 13 years [15]. The mean follow-up time for all women in this analysis was 4.98 years (range, 0.01 years to 9.33 years). The mean (SD) ages at entry and exit were 62.9 years (5.4) and 67.9 years (6.1), respectively. The total number of womanyears of observation was 389,714 .

Using Poisson regression in EPICURE software [16], we generated incidence rates and rate ratios (RRs) via standard likelihood ratio methods [17]. Age and calendar time were time-dependent but all other variables were timeindependent. We adjusted all RRs for attained age, calendar time, PLCO screening center, age at menarche, age at natural menopause, age at first birth and parity, firstdegree family history of breast cancer, benign breast disease, current height, and menopausal hormone therapy use. Complete-case analyses produced similar results (data not shown), so, unless noted, we present analyses that included all participants. We chose the final adjustment factors by comparing models and then dropping potential confounders (e.g., education, marital status, and others) whose presence did not substantially affect the parameter estimates. The final ratio of events to independent variables was approximately 20:1. Randomization produced nearly identical distributions of demographic and reproductive characteristics between arms, and further adjustment for trial arm did not change any results (data not shown).

\section{Results}

Most participants were white but nearly 7,000 (9.7\%) were non-white (Table 1). More than 9,000 women $(13.7 \%)$ reported having a mother, sister, or daughter with a history of breast cancer. More than 5000 women $(7.3 \%)$ first gave birth after age 30 . One third of the participants reported a surgical menopause, approximately one half used oral contraceptives, and two thirds used menopausal hormone therapy. Based on BMI from selfreported height and weight at baseline, one third of the population was overweight (BMI $\left.\geq 25 \mathrm{~kg} / \mathrm{m}^{2}\right)$ and approximately one quarter was obese $\left(B M I \geq 30 \mathrm{~kg} / \mathrm{m}^{2}\right)$ or severely obese $\left(B M I \geq 35 \mathrm{~kg} / \mathrm{m}^{2}\right)$.

As expected, age-specific breast cancer incidence rates rose with increasing age (Table 2). Compared with white women, African-American and Asian/Pacific Islander women were non-significantly more likely to develop breast cancer after adjustment for other factors (see table footnote). Increasing parity and earlier age at first birth were inversely associated with breast cancer. Later ages at menarche and natural menopause were inversely and positively, respectively, associated with breast cancer. Current menopausal hormone therapy use at baseline, regardless of duration, significantly increased risk, but the baseline questionnaire did not query hormone therapy formulation or regimen. Height, weight, and BMI were positively associated with breast cancer, although weight and BMI associations emerged only after statistical adjustment and only a few categories produced statistically significant associations.

\section{Discussion}

Our analysis of postmenopausal breast cancer in the PLCO study revealed interesting differences from the generally established epidemiology of breast cancer. Increasing age, parity, family history of breast cancer, and use of menopausal hormone therapy were all associated with breast cancer as expected. Associations with other key risk factors - age at menarche, age at menopause, and obesity - were slightly different from the previously published literature. These differences have at least two implications for ongoing and future research on breast cancer. 
Table I: Baseline characteristics for 70,575 women in the PLCO Cancer Screening Trial Cohort.

\begin{tabular}{|c|c|c|}
\hline & Number & $\%$ \\
\hline \multicolumn{3}{|l|}{ Age at baseline } \\
\hline $55-59$ & 24,381 & 34.6 \\
\hline $60-64$ & 21,405 & 30.3 \\
\hline $65-69$ & 15,405 & 21.8 \\
\hline $70-74$ & 9,384 & 13.3 \\
\hline \multicolumn{3}{|l|}{ Race/ethnicity } \\
\hline White & 62,425 & 88.5 \\
\hline African-American & 4,063 & 5.8 \\
\hline Asian/Pacific Islander & 2,754 & 3.9 \\
\hline Other* & 1,333 & 1.9 \\
\hline \multicolumn{3}{|l|}{ Education } \\
\hline Less than H.S. & 4,598 & 6.5 \\
\hline Completed H.S. & 28,588 & 40.5 \\
\hline Beyond H.S. & 37,215 & 52.7 \\
\hline Unknown & 174 & 0.3 \\
\hline \multicolumn{3}{|l|}{ Marital status } \\
\hline Married or living as married & 48,749 & 69.1 \\
\hline Widowed & 9,700 & 13.7 \\
\hline Divorced or separated & 9,616 & 12.7 \\
\hline Never married/missing & 2,510 & 4.5 \\
\hline \multicolumn{3}{|c|}{ Mother or sister with breast cancer } \\
\hline No & 57,214 & 81.1 \\
\hline Yes & 9,692 & 13.7 \\
\hline Unknown & 3,669 & 5.2 \\
\hline \multicolumn{3}{|l|}{ Age at menarche } \\
\hline$<12$ & 14,259 & 20.2 \\
\hline $12-13$ & 37,816 & 53.6 \\
\hline $14-15$ & 15,105 & 21.4 \\
\hline$\geq 16$ & 3,208 & 4.6 \\
\hline Missing & 187 & 0.3 \\
\hline \multicolumn{3}{|l|}{ Years of oral contraceptive use } \\
\hline None & 32,170 & 45.6 \\
\hline$<$ I year & 10,219 & 14.5 \\
\hline $2-3$ years & 7,636 & 10.8 \\
\hline $4-5$ years & 5,208 & 7.4 \\
\hline $6-9$ years & 6,303 & 8.9 \\
\hline$\geq 10$ years & 8,830 & 12.5 \\
\hline Missing & 209 & 0.3 \\
\hline \multicolumn{3}{|l|}{ Parity and age at first birth } \\
\hline Nulliparous & 6,454 & 9.1 \\
\hline \multicolumn{3}{|l|}{$1-2$} \\
\hline$<20$ years & 2,499 & 3.5 \\
\hline $20-24$ years & 9,336 & 13.2 \\
\hline $25-29$ years & 6,629 & 9.4 \\
\hline 30-34 years & 2,405 & 3.4 \\
\hline$\geq 35$ years & 1,021 & 1.5 \\
\hline \multicolumn{3}{|l|}{$3-4$} \\
\hline$<20$ years & 5,721 & 8.1 \\
\hline $20-24$ years & 16,227 & 23.0 \\
\hline $25-29$ years & 5,942 & 8.4 \\
\hline 30-34 years & 1,020 & 1.5 \\
\hline$\geq 35$ years & 343 & 0.5 \\
\hline \multicolumn{3}{|l|}{$\geq 5$} \\
\hline$<20$ years & 3,818 & 5.4 \\
\hline 20-24 years & 7,162 & 10.2 \\
\hline $25-29$ years & 1,506 & 2.1 \\
\hline 30-34 years & 193 & 0.3 \\
\hline$\geq 35$ years & 194 & 0.3 \\
\hline Missing or unknown & 105 & 0.2 \\
\hline
\end{tabular}

Table I: Baseline characteristics for $\mathbf{7 0 , 5 7 5}$ women in the PLCO Cancer Screening Trial Cohort. (Continued)

\begin{tabular}{|c|c|c|}
\hline \multicolumn{3}{|l|}{ Menopause Type } \\
\hline Natural & 43,572 & 61.7 \\
\hline Surgical & 23,312 & 3233.0 \\
\hline Radiation or medications & 2,346 & 3.3 \\
\hline Missing & 1345 & 41.9 \\
\hline \multicolumn{3}{|l|}{ Age at Natural Menopause } \\
\hline$<45$ years & 4,468 & 6.3 \\
\hline $45-49$ years & 11,175 & 15.8 \\
\hline 50-54 years & 22,134 & 31.4 \\
\hline $55+$ years & 5,709 & 8.1 \\
\hline Missing & 86 & 0.1 \\
\hline \multicolumn{3}{|c|}{ Menopausal hormone therapy use } \\
\hline None & 23,262 & 33.0 \\
\hline Former use & 11,435 & 16.2 \\
\hline Current use, $\leq 5$ years & 11,546 & 16.4 \\
\hline Current use, $>5$ years & 23,712 & 33.6 \\
\hline Missing & 620 & 0.9 \\
\hline \multicolumn{3}{|l|}{ Body Mass Index (BMI; kg/m²) } \\
\hline$<18.5$ & 892 & 1.3 \\
\hline $18.5-24.9$ & 27,251 & 38.6 \\
\hline $25-29$ & 24,214 & 34.3 \\
\hline $30-34.9$ & 11,102 & 15.7 \\
\hline$\geq 35$ & 6,297 & 8.9 \\
\hline Missing & 819 & 1.2 \\
\hline
\end{tabular}

First, the magnitude of some risk factor associations may be changing. Published studies have reported consistent, linear risk relationships with older ages at menarche (e.g.: $5 \%$ decrease in risk per 1-year delay after age 12) and menopause (e.g.: $3 \%$ increase in risk per 1 -year delay age at menopause) $[8,9,18]$. In contrast, we observed a fairly uniform decreased risk with older ages at menarche and a non-significant increased risk only in the oldest age-atmenopause group. The larger numbers of older women in the PLCO cohort could explain the lower RRs. Alternatively, inaccurate recall, especially among older women [19], or non-differential misclassification could be a factor, because our questionnaire collected only categorical data on these ages.

Body size is positively associated with postmenopausal breast cancer [20]. In a pooled analysis of cohort studies, risk increased significantly by $7 \%$ per $4-\mathrm{kg} / \mathrm{m}^{2}$ BMI increase, $7 \%$ per $5-\mathrm{cm}$ height increase, and $6 \%$ per $10-\mathrm{kg}$ weight increase [7]. In our analysis, all three factors increased the relative risks by $20 \%$. Despite the large sample size, only the RRs for the highest categories were statistically significant; the BMI association was stronger than the height and weight associations.

We observed a higher RR for breast cancer for the combination of low parity and later age at first birth, whereas an earlier meta-analysis reported declining RRs with lower parity in women whose first birth occurred at older ages 
Table 2: Number of breast cancers, person-years, rates, and RRs by demographic, reproductive, and anthropometric factors.

\begin{tabular}{|c|c|c|c|c|c|}
\hline & Breast Cancers* & Woman-Years & Crude Rate & $\mathrm{RR}^{* *}$ & $95 \% \mathrm{Cl}$ \\
\hline \multicolumn{6}{|l|}{ Attained Age } \\
\hline $55-59$ & 274 & 63,088 & 434.31 & 1.00 & Ref. \\
\hline $60-64$ & 608 & 108,640 & 559.65 & 1.36 & $1.18-1.57$ \\
\hline $65-69$ & 582 & 104,433 & 557.30 & 1.44 & $1.24-1.67$ \\
\hline $70-74$ & 434 & 79,134 & 548.44 & 1.48 & $1.26-1.73$ \\
\hline $75+$ & 187 & 34,419 & 543.30 & 1.47 & $1.21-1.79$ \\
\hline \multicolumn{6}{|l|}{ Race } \\
\hline White & $\mathrm{I}, 854$ & 345,926 & 535.95 & 1.00 & Ref. \\
\hline African-American & 89 & 19,765 & 450.29 & 1.05 & $0.84-1.32$ \\
\hline Asian/Pacific Islander & 111 & 17,230 & 644.23 & 1.14 & $0.86-|.5|$ \\
\hline Other/unknown & 31 & 6,793 & 456.35 & 0.92 & $0.64-1.32$ \\
\hline \multicolumn{6}{|c|}{ Family history of breast cancer } \\
\hline No & 1696 & 336,410 & 504.15 & 1.00 & Ref. \\
\hline Yes & 389 & 53,304 & 729.78 & 1.44 & $1.29-1.60$ \\
\hline \multicolumn{6}{|l|}{ Number of Live Births } \\
\hline 0 & 240 & 35,545 & 675.20 & 1.00 & Ref. \\
\hline I & 160 & 28,296 & 565.45 & 0.70 & $0.55-0.89$ \\
\hline 2 & 524 & 88,510 & 592.02 & 0.76 & $0.62-0.92$ \\
\hline 3 & 526 & 96,163 & 546.99 & 0.75 & $0.62-0.91$ \\
\hline 4 & 331 & 66,673 & 496.45 & 0.72 & $0.59-0.88$ \\
\hline $5+$ & 301 & 73,888 & 407.37 & 0.65 & $0.53-0.80$ \\
\hline \multicolumn{6}{|l|}{ Age at First Birth } \\
\hline None & 240 & 35,545 & 675.20 & 1.00 & Ref. \\
\hline$<20$ & 267 & 62,165 & 429.50 & 0.68 & $0.53-0.86$ \\
\hline $20-24$ & 901 & 181,709 & 495.85 & 0.74 & $0.59-0.91$ \\
\hline $25-29$ & 471 & 80,523 & 584.93 & 0.83 & $0.66-1.03$ \\
\hline $30-34$ & 148 & 20,822 & 710.79 & 1.03 & $0.81-1.31$ \\
\hline $35+$ & 47 & 6,894 & 681.75 & 1.02 & $0.74-1.41$ \\
\hline \multicolumn{6}{|l|}{ Age at Menarche } \\
\hline$<12$ years & 457 & 76,987 & 593.61 & 1.00 & Ref. \\
\hline $12-13$ years & 1099 & 209,082 & 525.63 & 0.86 & $0.77-0.97$ \\
\hline $14-15$ years & 439 & 84,595 & 518.94 & 0.85 & $0.74-0.97$ \\
\hline$\geq 16$ years & 88 & 17,874 & 492.34 & 0.81 & $0.65-1.02$ \\
\hline \multicolumn{6}{|l|}{ Age at Menopause } \\
\hline$<45$ years & 123 & 25,254 & 487.05 & 1.00 & Ref. \\
\hline $45-49$ years & 340 & 64,113 & 530.31 & 1.07 & $0.87-\mid .31$ \\
\hline 50-54 years & 700 & 126,080 & 555.20 & 1.12 & $0.92-1.35$ \\
\hline $55+$ years & 211 & 32,192 & 655.44 & 1.29 & $1.03-1.62$ \\
\hline Surgical menopause & 574 & 122,386 & 469.01 & 0.84 & $0.69-1.02$ \\
\hline Radiation/medication & 94 & $|2,06|$ & 779.37 & 1.32 & $1.01-1.74$ \\
\hline \multicolumn{6}{|c|}{ Menopausal hormone therapy use } \\
\hline Never & 571 & 134,329 & 425.08 & 1.00 & Ref. \\
\hline Former & 280 & 64,773 & 432.28 & 1.02 & $0.88-1.18$ \\
\hline Current, $<5$ years & 372 & 61,931 & 600.67 & 1.44 & $1.26-1.66$ \\
\hline Current, $\geq 5$ years & 847 & 125,006 & 677.57 & 1.67 & $1.49-1.87$ \\
\hline \multicolumn{6}{|l|}{ Weight $(\mathrm{kg})$} \\
\hline$<60$ & 437 & 82,961 & 526.75 & 1.00 & Ref. \\
\hline $60-64.9$ & 310 & 59,068 & 524.82 & 1.03 & $0.86-1.19$ \\
\hline $65-69.9$ & 311 & 56,091 & 554.46 & 1.18 & $0.97-1.30$ \\
\hline $70-74.9$ & 257 & 49,325 & 521.03 & 1.08 & $0.92-1.26$ \\
\hline $75-79.9$ & 267 & 47,072 & 567.22 & 1.21 & $1.03-1.42$ \\
\hline$\geq 80$ & 486 & 91,892 & 528.88 & 1.20 & $1.04-1.38$ \\
\hline \multicolumn{6}{|l|}{ Height (m) } \\
\hline$<1.60$ & 527 & 101,460 & 519.42 & 1.00 & Ref. \\
\hline $1.60-1.64$ & 605 & 117,236 & 516.05 & 1.01 & $0.89-1.13$ \\
\hline $1.65-1.69$ & 561 & 102,205 & 548.90 & 1.06 & $0.94-1.20$ \\
\hline$\geq 1.70$ & 385 & 66,707 & 577.15 & 1.11 & $0.97-1.27$ \\
\hline \multicolumn{6}{|l|}{ BMI $\left(\mathrm{kg} / \mathrm{m}^{2}\right)$} \\
\hline$<18.5$ & 25 & 5,135 & 486.85 & 0.88 & $0.59-1.32$ \\
\hline $18.5-24.9$ & 848 & 154,447 & 549.06 & 1.00 & Ref. \\
\hline
\end{tabular}


Table 2: Number of breast cancers, person-years, rates, and RRs by demographic, reproductive, and anthropometric factors. (Continued)

\begin{tabular}{|c|c|c|c|c|c|}
\hline $25-29$ & 712 & 133,799 & 532.14 & 1.06 & $0.95-1.17$ \\
\hline $30-34.9$ & 305 & 59,109 & 516.00 & 1.10 & $0.97-1.26$ \\
\hline$\geq 35$ & 173 & 32,478 & 532.67 & 1.21 & $1.02-1.43$ \\
\hline
\end{tabular}

* Includes confirmed invasive cancers, confirmed in situ lesions, and self-reported cancers.

** Adjusted for attained age, screening center, age at menarche, age at menopause, family history of breast cancer, benign breast disease, height, and menopausal hormone therapy (all in categories as shown in the table), plus combined age at first birth and parity (nulliparous or first birth after 35 years, first birth before age 25 , first birth 25-34 years, or unknown) and calendar time (5/3I//993 - 5/3I//995, 6/1/1995 - 5/3I/I997, 6/I//997 - 5/ $3 \mathrm{I} / \mid 999,6 / \mathrm{I} / \mathrm{I} 999-5 / 3 \mathrm{I} / 200 \mathrm{I}$, and $6 / \mathrm{I} / 200 \mathrm{I}-5 / 3 \mathrm{I} / 2003)$. RRs for age at first birth and parity were adjusted for the other factor.

Not shown are unknown parity ( 3 breast cancers and 638 person-years), age at first birth (II breast cancers and 2,635 person-years), age at menarche ( 2 breast cancers and I,I 77 person-years), age at or type of menopause (43 breast cancers and 7,628 person-years), menopausal hormone therapy use ( 15 breast cancers and 3,676 person-years), weight ( 17 breast cancers and 3,304 person-years), height ( 7 breast cancers and 2, 107 person-years), and BMI (22 breast cancers and 4,747 person-years).

[21]. Both that and our study included few multiparous women who first gave birth after age 35 .

These changes could reflect underlying demographic changes. Mean age of menarche among U.S. females has declined in recent decades, whereas later age at natural menopause is more common than before $[22,23]$. The prevalence of women who first give birth after age 35 is increasing, as is the prevalence of obesity [24]. These factors are potentially related: obesity might spark early estrogen production and the onset of puberty, whereas parity and BMI are also associated with later age at menopause [25-28]. Teasing apart the quantitative effect of these changes on risk factor associations, as well as the underlying biologic implications, may prove to be a challenge.

Changing distributions of risk factors will affect the use of risk prediction models that project individual probabilities of breast cancer and influence eligibility for clinical trials. The widely used Gail model [29] relies on readily available medical information, such as age at first birth and age at menopause. Modified prediction models incorporate additional clinical information, such as breast density [30]. If the relative risk measures that underlie the projection of absolute risks in these models are changing, then there is the potential for the models to lose some of their current calibratory and discriminatory ability. Continued assessment of model performance among newer population-based studies with diverse populations could address this and shed further light on the potential influence of changing demographics on the epidemiology of postmenopausal breast cancer.

The known risk factors for breast cancer account for perhaps only $50 \%$ of the population burden of breast cancer [31]. A polygenic model of breast cancer hypothesizes that many genetic factors contribute individually small but collectively large effects that could explain the remaining $50 \%$ of the population attributable risk [32]. Based on extensive results to date of candidate pathways, the overall effect of low-penetrance SNPs is minimal [33]. The SNPbased associations that have emerged from marker-based scans have unknown function or functions unrelated to the hormonal pathways linked with breast cancer $[34,35]$. Other important genetic markers with relevant functions might surface. Exploration of genetic factors is likely to be most fruitful if placed within the context of the known risk factors for breast cancer, both to see whether markers modify those risks or are independently associated with those risk factors [11].

Whether known or future genetic markers can improve the performance of existing risk prediction models - or potential new models that incorporate the clinical heterogeneity of breast cancers [36]-is uncertain. Readily available lifestyle or questionnaire-based information, such as reproductive history, will remain the cornerstone of risk prediction and stratification even if it becomes easy, inexpensive, and risk-free for large numbers of women to determine their genetic profile because the small-magnitude risk associations are unlikely to be useful for prediction $[37,38]$. Changes in the underlying associations between those risk factors and breast cancer would not adversely affect such evaluation, but it would require continued surveillance of breast cancer epidemiology among contemporary populations, such as PLCO, both individually and within large-scale replication efforts [32].

Our large sample size makes it unlikely that the deviations from expectation that we observed were due to chance. Overall exposure and endpoint data were likely good, but residual confounding might exist. The questionnaire lacked information on some risk factors, such as breastfeeding [8], physical activity [39], and alcohol use [40]. For others - particularly menopausal hormone therapy [41] - the baseline questionnaire did not allow us to differentiate the higher-risk estrogen-plus-progestin formulations from estrogen-only formulations. Compared with 2001 U.S. Census Bureau data on women aged 55-74 [42], lower percentages of PLCO participants reported receiving some formal education beyond high school across all racial/ethnic groups: $58 \%$ vs. $53 \%$ for whites, $67 \%$ vs. $52 \%$ for African-Americans, and $57 \%$ vs. $52 \%$ for Asian/Pacific Islanders. We cannot rule out that other unmeasured factors may make our study population 
slightly different from the U.S. population on the whole. Our analysis covered a relatively short follow-up, and continued follow-up of the PLCO population may confirm both the validity and generalizability of our findings.

\section{Conclusion}

In conclusion, this study of over 75,000 post-menopausal women suggests that population-level and demographic changes might influence the magnitude of well-established associations between certain recognized risk factors and breast cancer. These potential changes may become increasingly important as new molecular epidemiologic efforts attempt to expand upon existing methods for understanding relative and absolute risks for breast cancer.

\section{Competing interests}

The authors declare that they have no competing interests.

\section{Authors' contributions}

JVL and PH designed the investigation. JVL analyzed the data. JVL, ARK, SSB, PMM, SCC, MFL, RNH, PCP, CDB and $\mathrm{PH}$ interpreted the results. JVL, ARK, SSB, CDB, and PD drafted the manuscript, and JVL, ARK, SSB, PMM, SCC, MFL, RNH, PCP, CDB, and PH edited the manuscript.

\section{Acknowledgements}

The authors thank Drs. Richard Hayes and John K. Gohagan of the National Cancer Institute, the Screening Center investigators and staff of the Prostate, Lung, Colorectal, and Ovarian (PLCO) Cancer Screening Trial, and Mr. Thomas L. Riley and Craig Williams and staff of IMS, Inc., Silver Spring, MD. This work was supported by National Cancer Institute intramural and extramural funds and by individual contracts from the National Cancer Institute to each of the 10 screening centers and to the coordinating center.

\section{References}

I. Hartge P: Genes, hormones, and pathways to breast cancer. N Engl J Med 2003, 348:2352-2354.

2. Hankinson SE, Colditz GA, Willett WC: Towards an integrated model for breast cancer etiology: the lifelong interplay of genes, lifestyle, and hormones. Breast Cancer Res 2004, 6:213-218.

3. Rockhill B, Weinberg CR, Newman B: Population attributable fraction estimation for established breast cancer risk factors: considering the issues of high prevalence and unmodifiability. Am J Epidemiol 1998, 147:826-833.

4. Familial breast cancer: collaborative reanalysis of individual data from 52 epidemiological studies including 58,209 women with breast cancer and 101,986 women without the disease. Lancet 200I, 358:1389-1399.

5. Albrektsen G, Heuch I, Hansen S, Kvale G: Breast cancer risk by age at birth, time since birth and time intervals between births: exploring interaction effects. $\mathrm{Br}$ J Cancer 2005, 92:167-175.

6. Beral V: Breast cancer and hormone-replacement therapy in the Million Women Study. Lancet 2003, 362:419-427.

7. Brandt PA van den, Spiegelman D, Yaun SS, Adami HO, Beeson L, Folsom AR, Fraser G, Goldbohm RA, Graham S, Kushi L, et al.: Pooled analysis of prospective cohort studies on height, weight, and breast cancer risk. Am J Epidemiol 2000, 152:5 I4-527.

8. Collaborative Group on Hormonal Factors in Breast Cancer: Breast cancer and breastfeeding: collaborative reanalysis of individual data from 47 epidemiological studies in 30 countries, including 50302 women with breast cancer and 96973 women without the disease. Lancet 2002, 360(9328): $187-195$.

9. Hunter DJ, Spiegelman D, Adami HO, Brandt PA van den, Folsom AR, Goldbohm RA, Graham S, Howe GR, Kushi LH, Marshall JR, et al: Non-dietary factors as risk factors for breast cancer, and as effect modifiers of the association of fat intake and risk of breast cancer. Cancer Causes Control 1997, 8:49-56.

10. Key T, Appleby P, Barnes I, Reeves G: Endogenous sex hormones and breast cancer in postmenopausal women: reanalysis of nine prospective studies. J Natl Cancer Inst 2002, 94:606-616.

II. Chanock SJ, Hunter DJ: Genomics: when the smoke clears. Nature 2008, 452:537-538.

12. Hayes RB, Reding D, Kopp W, Subar AF, Bhat N, Rothman N, Caporaso N, Ziegler RG, Johnson CC, Weissfeld JL, et al.: Etiologic and early marker studies in the prostate, lung, colorectal and ovarian (PLCO) cancer screening trial. Control Clin Trials 2000, 21:349S-355S.

13. Prorok PC, Andriole GL, Bresalier RS, Buys SS, Chia D, Crawford ED, Fogel R, Gelmann EP, Gilbert F, Hasson MA, et al: Design of the Prostate, Lung, Colorectal and Ovarian (PLCO) Cancer Screening Trial. Control Clin Trials 2000, 21:273S-309S.

14. Moher D, Schulz KF, Altman D: The CONSORT statement: revised recommendations for improving the quality of reports of parallel-group randomized trials. JAMA 200I, 285: $1987-199 \mid$.

15. Gohagan JK, Prorok PC, Hayes RB, Kramer BS: The Prostate, Lung, Colorectal and Ovarian (PLCO) Cancer Screening Trial of the National Cancer Institute: history, organization, and status. Control Clin Trials 2000, 2 I:25IS-272S.

16. Preston DL, Lubin J, Pierce DA, McConney ME: EPICURE [software] Seattle, WA: HiroSoft International Corp; 1996.

17. Breslow NE, Day NE: Statistical methods in cancer research. The design and analysis of cohort studies Volume II. Lyon: International Agency for Research on Cancer; 1987.

18. Collaborative Group on Hormonal Factors in Breast Cancer: Breast cancer and hormone replacement therapy: collaborative reanalysis of data from from $5 \mathrm{I}$ epidemiological studies of 52,705 women with breast cancer and 108,411 women without breast cancer. Lancet 1997, 350: 1047-1059. Erratum in: Lancet 1997 I5;350(9089): 1484

19. Rockhill B, Colditz GA, Rosner B: Bias in breast cancer analyses due to error in age at menopause. Am J Epidemiol 2000, | 5 |:404-408.

20. Ahlgren M, Melbye M, Wohlfahrt J, Sorensen TI: Growth patterns and the risk of breast cancer in women. N Engl J Med 2004, $351: 1619-1626$

21. Ewertz M, Duffy SW, Adami HO, Kvale G, Lund E, Meirik O, Mellemgaard $\mathrm{A}$, Soini I, Tulinius $\mathrm{H}$ : Age at first birth, parity and risk of breast cancer: a meta-analysis of 8 studies from the Nordic countries. Int J Cancer 1990, 46:597-603.

22. McDowell MA, Brody DJ, Hughes JP: Has age at menarche changed? Results from the National Health and Nutrition Examination Survey (NHANES) 1999-2004. J Adolesc Health 2007, 40:227-231.

23. Nichols HB, Trentham-Dietz A, Hampton JM, Titus-Ernstoff L, Egan KM, Willett WC, Newcomb PA: From menarche to menopause: trends among US Women born from 1912 to 1969. Am J Epidemiol 2006, 164:1003-1011.

24. Matthews TJ, Hamilton BE: Mean age of mother, 1970-2000. Nat Vital Stat Rep 2002, 5 I (I): I-16.

25. de Waard F, Thijssen JH: Hormonal aspects in the causation of human breast cancer: epidemiological hypotheses reviewed, with special reference to nutritional status and first pregnancy. I Steroid Biochem Mol Biol 2005, 97:45 I-458.

26. Kaplowitz PB: Link between body fat and the timing of puberty. Pediatrics 2008, I2I(Suppl 3):S208-S217.

27. Ortiz AP, Harlow SD, Sowers M, Nan B, Romaguera J: Age at natural menopause and factors associated with menopause state among Puerto Rican women aged 40-59 years, living in Puerto Rico. Menopause 2006, I 3: I 16- 124.

28. Hardy R, Mishra GD, Kuh D: Body mass index trajectories and age at menopause in a British birth cohort. Maturitas 2008, 59(4):304-3।4.

29. Gail MH, Brinton LA, Byar DP, Corle DK, Green SB, Schairer C, Mulvihill JJ: Projecting individualized probabilities of developing 
breast cancer for white females who are being examined annually. J Natl Cancer Inst 1989, 8 I: I879-I886.

30. Chen J, Pee D, Ayyagari R, Graubard B, Schairer C, Byrne C, Benichou J, Gail $\mathrm{MH}$ : Projecting absolute invasive breast cancer risk in white women with a model that includes mammographic density. J Natl Cancer Inst 2006, 98:1215-1226.

31. Madigan MP, Ziegler RG, Benichou J, Byrne C, Hoover RN: Proportion of breast cancer cases in the United States explained by well-established risk factors. I Natl Cancer Inst 1995, 87: $|68|-\mid 685$

32. Hunter DJ, Riboli E, Haiman CA, Albanes D, Altshuler D, Chanock SJ, Haynes RB, Henderson BE, Kaaks R, Stram DO, et al.: A candidate gene approach to searching for low-penetrance breast and prostate cancer genes. Nat Rev Cancer 2005, 5:977-985.

33. Pharoah PD, Tyrer J, Dunning AM, Easton DF, Ponder BA: Association between common variation in 120 candidate genes and breast cancer risk. PLoS Genet 2007, 3:e42.

34. Hunter DJ, Kraft P, Jacobs KB, Cox DG, Yeager M, Hankinson SE Wacholder S, Wang Z, Welch R, Hutchinson A, et al:: A genomewide association study identifies alleles in FGFR2 associated with risk of sporadic postmenopausal breast cancer. Nat Genet 2007, 39:870-874.

35. Cox A, Dunning AM, Garcia-Closas M, Balasubramanian S, Reed MW, Pooley KA, Scollen S, Baynes C, Ponder BA, Chanock S, et al.: A common coding variant in CASP8 is associated with breast cancer risk. Nat Genet 2007, 39:352-358.

36. Gail MH, Anderson WF, Garcia-Closas M, Sherman ME: Absolute risk models for subtypes of breast cancer. J Natl Cancer Inst 2007, 99: 1657-1659.

37. Hunter DJ, Khoury MJ, Drazen JM: Letting the genome out of the bottle - will we get our wish? $N$ Engl J Med 2008, 358: I05-107.

38. Haga SB, Willard HF, Audeh MW, Hunter DJ, Khoury MJ, Drazen JM: Letting the genome out of the bottle. N Engl J Med 2008, 358:2184-2185.

39. Monninkhof EM, Elias SG, Vlems FA, van dT I, Schuit AJ, Voskuil DW van Leeuwen FE: Physical activity and breast cancer: a systematic review. Epidemiology 2007, I 8:137-I57.

40. Smith-Warner SA, Spiegelman D, Yaun SS, Brandt PA van den, Folsom AR, Goldbohm RA, Graham S, Holmberg L, Howe GR, Marshall JR, et al.: Alcohol and breast cancer in women: a pooled analysis of cohort studies. JAMA 1998, 279:535-540.

41. Breast cancer and hormone replacement therapy: collaborative reanalysis of data from 5 I epidemiological studies of 52,705 women with breast cancer and $108,4 I I$ women without breast cancer. Collaborative Group on Hormonal Factors in Breast Cancer. Lancet 1997, 350:1047-1059. Erratum in: Lancet 1997 15;350(9089): |484.

42. U.S. Census Bureau [http://www.census.gov]

\section{Pre-publication history}

The pre-publication history for this paper can be accessed here:

http://www.biomedcentral.com/1471-2407/9/84/prepub
Publish with Biomed Central and every scientist can read your work free of charge

"BioMed Central will be the most significant development for disseminating the results of biomedical research in our lifetime. "

Sir Paul Nurse, Cancer Research UK

Your research papers will be:

- available free of charge to the entire biomedical community

- peer reviewed and published immediately upon acceptance

- cited in PubMed and archived on PubMed Central

- yours - you keep the copyright
BioMedcentral 